\title{
Are all brain functions computable?
}

\begin{abstract}
Background Whether the human brain is nothing but an advanced computer is a matter of inconclusive debate. This paper contributes to that debate.

Method Critical reasoning based on evidence provided by the history of a woman who complained of amnesia after each of two separate acts of attempted suicide.

Findings A life-threatening tendency (suicidal impulses) may be countered by a functional imperfection (selective amnesia) or a feigned malfunction (malingering).

Interpretation Some aspects of brain function may depend on operations that no hitherto invented computer can duplicate.

\section{Introduction}

Ever since Alan Turing asked the famously provocative question, Can machines think? the human brain has been characterised by some as a "thinking machine" (1). Many brain processes including those involved in doing arithmetic and seeing objects have been modelled on computer programs (2). The question this paper explores is whether there are aspects of brain function which defy analysis in terms of the concept of computability (2).
\end{abstract}

\section{The story}

A 43 year old housewife, married for 21 years, was brought to hospital in a coma induced by an overdose of pentobarbitone tablets. During the preceding 7 years, she had 3 episodes of reactive depression related to marital discord. There was no past history of overt hysterical behaviour or of alcoholism. A note written by her stated that she had decided to end her life because her husband "no longer cared for her".

On recovering consciousness, she appeared to have an amnesia which encompassed the preceding 13 years. The amnesia did not abolish her sense of personal identity, although it seemed to impose a bothersome inconvenience on her interactions with others. She appeared to be cheerful, and seemed to have no memory of her suicidal attempt. On discharge from hospital she went home with her husband, and did not report for psychiatric follow up.

About 6 months later, she was again brought to hospital in a coma induced by swallowing pentobarbitone tablets. According to her husband, about 5 months after her first suicidal attempt, she had gradually recovered her lost memory and before long had become depressed about the same problem. Within a fortnight of regaining her memory completely, she had made the second suicidal attempt that brought her to hospital. On recovering consciousness, she complained of amnesia which encompassed the preceding 10 years. She seemed to have no memory of her suicidal attempts, appeared to be cheerful, and retumed home to live with her husband. 


\section{Discussion}

In his Hitchcock Lectures (1964) J Z Young hypothesised that brains are computers of homeostats of living things that keep them alive (3). When he gave the Gifford Lectures (1976-77), however, he asserted that the working of the brain cannot be understood in detail by analogy with computers (4). In the interim, he had come to regard the brain simply as an instrument for answering the continuously recurring question: "What is it best to do under these circumstances in order to promote the continuity of life?"(5). But the conundrum remains: how does the instrument work? Does it work like a massively parallel general purpose digital computer? Or does the operation of what philosophers of language cell intentionality (6) and the experience of subjective feelings inextricably associated with some aspects of brain function make it uniquely different from every non-living machine?

In the present case, after each act of attempted suicide provoked by painful memories the patient appeared to have acquired an amnesia. If it was real, then this functional impairment was life-saving because it prevented certain memories, including suicide provoking ones, from reaching her consciousness. Amnesia is not a documented after-effect of the use of barbiturates for sedation, hypnosis, anti-convulsant therapy or anaesthesia (7). Nor is amnesia a recognised symptom of pentobarbitone poisoning (7). Suppression of unpleasant memories is, of course, a long recognised capacity of the human brain. For example, when Romeo was heart-broken with unrequited love for Rosalind, his cousin Benvolio prescribed the remedy: "Be rul'd by me: forget to think of her". And when Romeo pleaded: "O teach me how I should forget to think", Benvolio described the way: "By giving liberty unto thine eyes. Examine other beauties" (8). It is reasonable to suppose that, if at all, the pentobarbitone overdose merely triggered an existing amnestic mechanism. An illuminating analogy is to hand. Opium relieves pain supposedly by interacting with opioid receptors in the brain. The same receptors also interact with endorphins and enkephalins generated in the brain itself to relieve pain. Thus an external agent (opium) may activate an internal analgesic mechanism. In like manner, the nearly lethal overdose of pentobarbitone may have activated an intrinsic amnestic mechanism.

Whether this patient's amnesia was chemically induced or whether she was in a state of hysterical fugue, the central relevant fact is that so long as the amnesia appeared to last she was not manifestly suicidal. The possibility that she was feigning amnesia ie. malingering, cannot, of course, be ruled out. Hence the differential diagnosis of her life-saving mental state during the periods she complained of amnesia after two suicidal attempts should include selective amnesia and malingering.

If she was genuinely amnestic and amnesia promoted the continuity of her life, then her brain had clearly traded off a slice of its memory for a lease of life, as if it had struck a kind of Faustian bargain with the devil of imperfection to promote the continuity of life. Such a capacity may well be in the repertoire of an organ capable of cognition, volition, self-consciousness and creativity. Alternatively, if she survived by malingering, then her brain was operating like an instrument endowed with a species of intentionality that enables one to "smile and smile and be a villain" (9), exemplifying Immanuel Kant's dictum that "Out of the crooked timber of humanity no straight thing can ever be made" (10).

At all events, her brain had countered a life-threatening tendency (suicidal impulses) either by strategically incurring a functional imperfection (selective amnesia) or by a feigned malfunction (malingering), both of which are beyond the power of any hitherto invented computer to imitate. So the answer to the question that forms the title of this paper is a firm, if not a categorical, no.

\section{Acknowledgements}

For their critical comments I thank the clinical staff of the Psychiatric Department, Hillingdon Hospital, Uxbridge, Middlesex, UK where the first draft of this paper was written in 1974.

\section{References}

1. Turing AM. Computing machinery and intelligence. Mind 1950; 59: 236. Reprinted in: Hofstadter DR, and Dennet DC, eds. The Mind's I. Middlesex: Basic Books, 1981.

2. Johnson Laird P. The computer and the mind. 2 nd ed. London: Fontana Press, 1993.

3. Young JZ. The memory system of the brain. Oxford: Oxford University Press, 1966.

4. Young JZ. Programs of the brain. Oxford: Oxford University Press, 1978.

5: Young JZ. An introduction to the study of man. Oxford: Clarendon Press, 1971.

6. Searle JR. Minds, brain and programs. Behavioral and Brain Sciences 1980; 3: 417-24.

7. Goodman and Gilman. The pharmacological basis of therapeutics. 8th ed. New York: Mc Graw-Hill, 1992.

8. Shakespeare W. Romeo and Juliet. Act 1, Scene 1.

9. Shakespeare W. Hamlet, Prince of Denmark. Act 1, Scene V.

10. The Oxford Dictionary of Quotations. 3rd ed. London: Oxford University Press, 1985.

Carlo Fonseka, Professor Emeritus, University of Kelaniya and University of Colombo. 